\title{
INCREASING PERFORMANCE AND ENERGY EFFICENCY OF A MACHINE TOOL THROUGH HYDROSTATIC LINEAR GUIDEWAYS WITH SINGLE DIGIT MICROMETRE FLUID FILM THICKNESS
}

\author{
M. Fritz ${ }^{* 1}$, M. Groeb ${ }^{1,2}$ \\ ${ }^{1}$ Kern Microtechnik GmbH, Eschenlohe, Germany \\ ${ }^{2}$ Technical University Darmstadt, Institute of Materials Science, Germany \\ *Corresponding author; e-mail: matthias.fritz@kern-microtechnik.com
}

\begin{abstract}
Ever increasing requirements to machine tool performance lead to a shift from regular roller bearing towards hydrostatic guideways. These have many advantageous properties, such as non-existent stick and slip, nearly no wear, while increasing dampening and stiffness. Compared to traditional guideways, hydrostatic have a constant energy demand, resulting from pump losses. The pump losses are composed out of the pressure and the flow rate of the fluid. The flowrate can be influenced with the third power via the fluid film thickness. For this, a novel micro gap design is proposed and tested. The static and dynamic stiffness and the power consumption are analysed and compared.
\end{abstract}

Keywords:

Hydrostatic; guideway; machine tool; precision; microgap; energy efficiency

\section{INTRODUCTION}

High precision machine tools have been using hydrostatic guideways for several decades [Bassani 1992]. Their advantages such as low friction [Liu 2017], high stiffness and good dampening behaviour can be used to reach extreme precision on machining centres [Hale 1991] [Knapp 2011]. Disadvantageous is the complex periphery as well as the constant energy requirements for the film upkeep [Wasson 2007]. For this reason, hydrostatic guideways and bearings are rarely used in smaller machine tools, and mostly in large machining centres where the relative investment cost plays a subordinate role. The cost for the conditioning of the working fluid increases the operating cost [Rowe 1970], but moreover also requires energy which is opposite towards greener machining. One approach towards reducing the energy consumption and operative cost is the reduction of the fluid film thickness [Elwell 1960]. By reducing the gap height, the flowrate is reduced, enabling smaller aggregates, while also decreasing the energy demand and thus lowering the investment and operative cost. A hinderance towards small gap designs is the increased requirements towards tolerances, making the manufacturing more difficult and expensive. Smaller fluid film thickness would also increase the advantages of hydrostatic guideways, by better stiffness and higher dampening [Rowe 1980] [Ghosh 1982] [Hunt 1963]. Current systems only use gap heights down to 20 $\mu \mathrm{m}$. This paper analyses a novel thin film hydrostatic guideway for its static and dynamic stiffness as well as power consumption.

\section{METHOD DESCRIPTION}

\subsection{Hydrostatic guideway working principle}

In hydrostatic guideways, the individual surfaces are separated via an externally supplied fluid [Rowe 1992]. Fig. 1 shows the principle of a hydrostatic bearing pad. The bearing consists out of the parts (1) and (2). By imagining part (2) as fixed, part (1) can be moved relative to this. Part (2) is fed with a pressurized fluid, creating a pocket with a projected surface $A$. The bearing is loaded by the force $W$. In Fig. 1a both parts are resting on each other. By supplying the fluid, the pocket pressure $p_{t}$ rises (Fig. 1b). Once the equilibrium of the lifting condition (equation 1) is reached, part (1) lifts. A fluid film builds up, separating the contact between part (1) and (2). Through the pressure step $L$, a volume flow $Q$ is delivered. Varying loads lead to different values in the film thickness (gap height) $h$ (Fig. 1d-f).

$$
p_{t}=\frac{W}{A}
$$



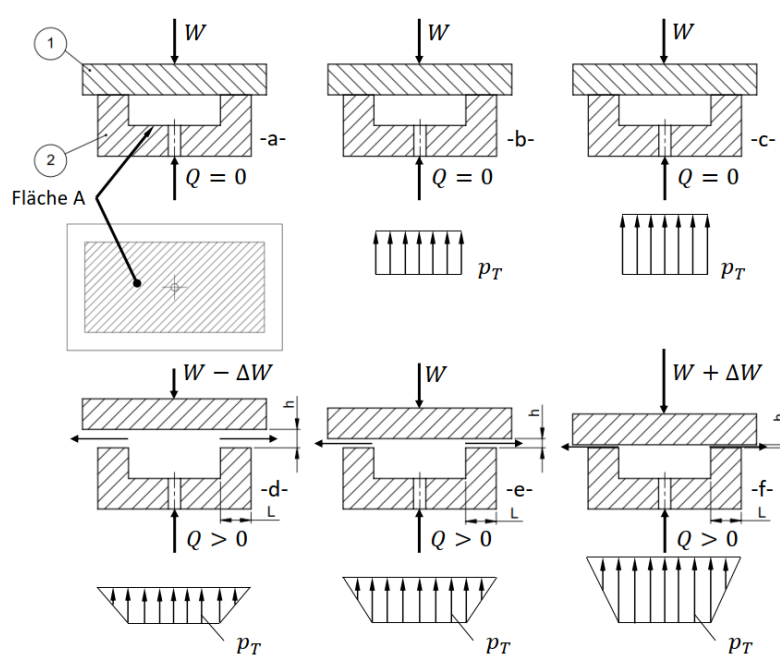

Fig. 1: Working principle of a hydrostatic bearing, after [Bassani 1992]

It is easily deductible that a hydrostatic bearing can only accept loads from one direction. A common approach is therefore to apply a preload, either via opposing pockets, vacuum, magnetism, gravitational or spring loading, enabling tensile loading. If the guideway has to withstand torque moments, multiple pockets are combined [Tonshoff 1995] [Weck 2006].

Each hydrostatic bearing pocket needs to be hydraulically isolated from others. This task is usually assigned to the fluid supply system, for example "pump per pocket" or a compensating device (restrictor) [Weck 2006] [Perovic 2012].

This paper focuses on the laminar (capillary) restrictor. It is characterized by having a single pump to supply all bearing pockets (Fig. 2).

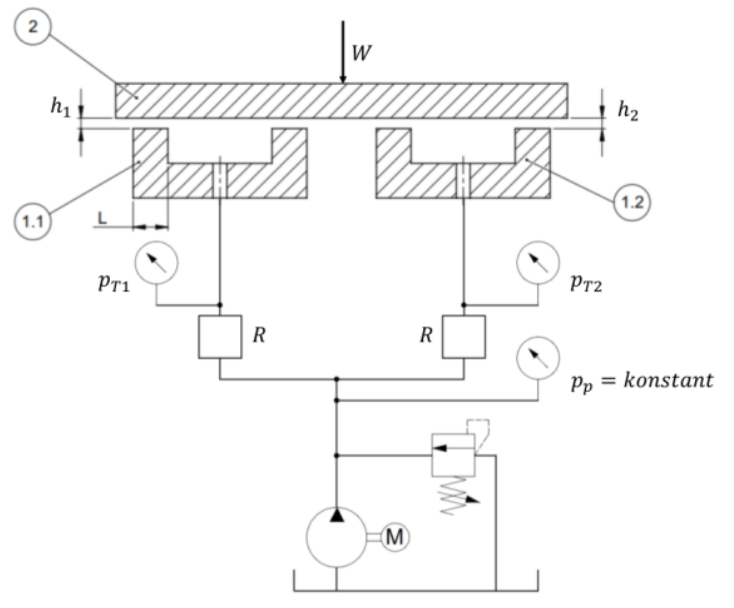

Fig. 2: system with laminar restrictor after [Bassani 1992]

The pump pressure is limited and therefore kept constant via a pressure relief valve. In order to isolate the individual hydrostatic bearings, a hydrostatic resistance $R$ is inserted into the supply lines. The flow inside this resistor is laminar, this means the pressure drop is proportional to the flowrate Q.

Through the reduction of the gap height towards a micro gap design, certain advantages appear. For a system with a laminar restrictor, equations 2 apply.

$Q \sim \frac{h^{3}}{\mu} \quad K \sim \frac{1}{h}$

$P_{\text {frict }} \sim \mu \frac{1}{h} \quad B \sim \frac{\mu}{h^{3}}$

For an optimised system, the frictional power $P_{\text {frict }}$ should be low, to avoid thermal effects and reduce the drive power requirements. The stiffness $\mathrm{K}$ and the dampening $\mathrm{B}$ should be as large as possible to achieve low deflections. Through a reduction of the gap height $h$, all properties except the friction can be positively influenced. A reduction of the viscosity $(\mu)$ can counteract the increase in friction. Thusly, a friction neutral optimization leads towards a linear increase in stiffness, an increase of the dampening with the second power and a decrease of the flowrate $Q$ with the second power. A low flowrate is advantageous for a low power consumption, as the pump power requirements are decreased.

\subsection{Theoretical static modelling}

The static model (see fig. 3) is a straightforward model that uses the same formulars as the model of regular hydrostatic single pocket bearings.

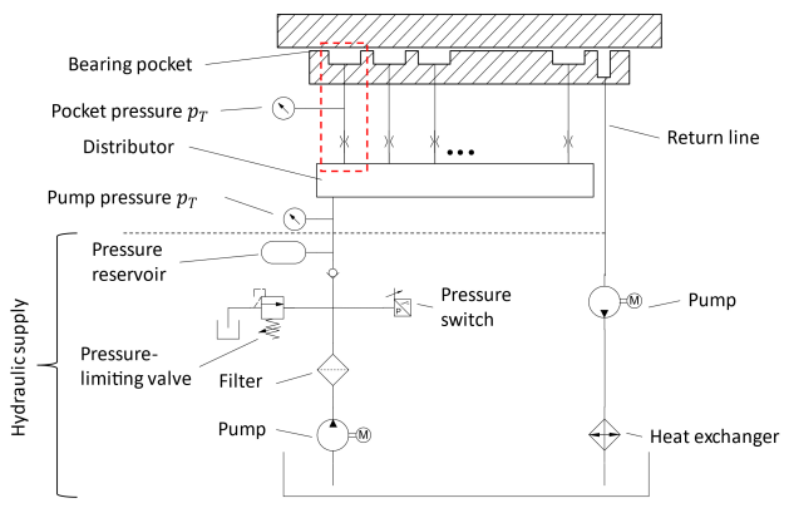

Fig. 3: Hydraulic circuit and system limits of the model, after [Wasson 2007].

Because all static outputs are based on the hydraulic resistances of the bearing gap and the capillary restrictor, the model takes the pump pressure $p_{p}$, the static pressure $p_{\text {To }}$ in the bearing pocket, the static load $F_{0}$, the effective bearing area $A_{\text {eff, }}$ the hydraulic resistance $R_{c}$ of the capillary and the static resistance $R_{T o}$ of the bearing gap into account. Equation 3 shows how the initial gap size $h_{0}$ is calculated.

$h_{0}=\left(p_{p}-p_{T_{0}}\right) \cdot R_{0} \cdot R_{C} \cdot \frac{A_{e f f}}{F_{0}} \quad$ with $R_{0}=R_{T_{0}} \cdot H_{0}^{3}$ 


\section{HSM \\ 2021 \\ MM Science Journal | www.mmscience.eu \\ ISSN 1803-1269 (Print) | ISSN 1805-0476 (Online) \\ Special Issue | HSM 2021 \\ $16^{\text {th }}$ International Conference on High Speed Machining \\ October 26-27, 2021, Darmstadt, Germany}

DOI: 10.17973/MMSJ.2021_11_2021175

\subsection{Theoretical dynamic modelling}

Because the properties of hydrostatic guideways such as stiffness, dampening, but also the power loss through excessive flow rate can be improved by reducing the fluid film thickness, the proposed micro gap linear hydrostatic in the single digit micrometre range shows clear improvements over traditional hydrostatic guideways, which have film thickness reaching down towards $20 \mu \mathrm{m}$.

Since research on micro gap linear hydrostatics has not been scientifically published before, a new dynamic model is created and compared to experimental validation. The model simulates a single bearing pad with a capillary flow restrictor. Assumed are a ridged moving mass, a constant pump pressure and constant preload as well as constant fluid characteristics.

Fig. 4 shows the dynamic model is based on the hydraulic state variables of the system. The central change is to consider the capacity of the hydraulic volume between the flow restrictor and the bearing. The pocket pressure $p_{T}$ changes depending on the volume flow through the pocket and the capillary restrictor. The resulting force of the pocket pressure acts on the moving mass and is therefore used in the motion equation as the stiffness force of the pocket.

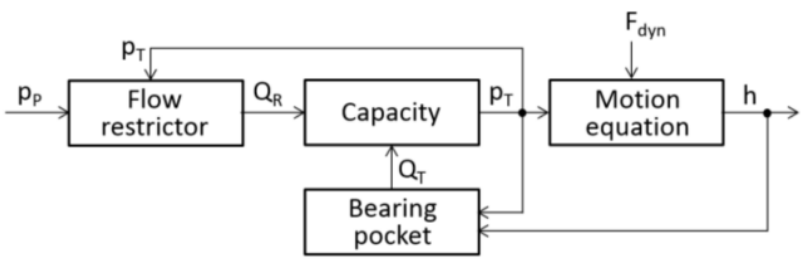

Fig. 4: Structure of the dynamic model.

\subsection{Hydraulic test stand}

In order to have a repeatable test environment, a hydraulic test stand was designed and build (Fig. 5, sectional view, Fig. 6, photograph).

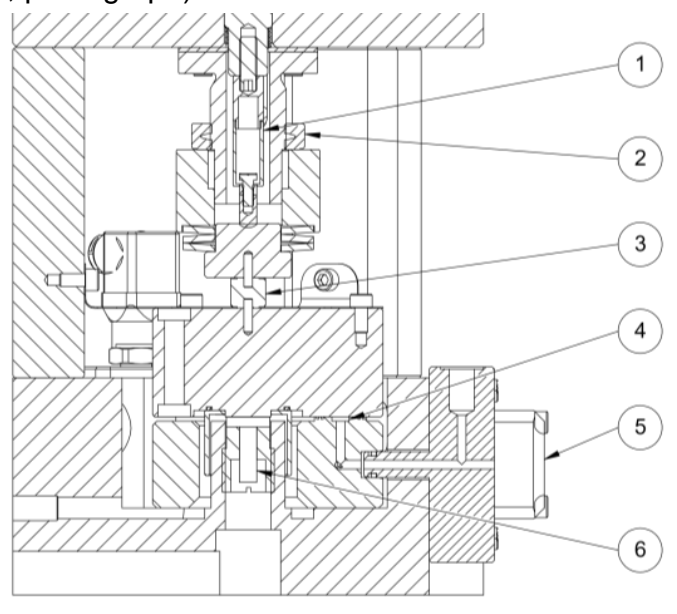

Fig. 5: Test setup, with: (1) piezo actuator (2) preload nut (3) piezo sensor (4) bearing pocket (5) restrictor adapter (6) capacitive sensor.
The preload can be created via a threaded nut. A piezo actuator optionally creates additional dynamic load. A force sensor measures the sum of both loads, enabling a repeatable setup. The gap height is measured via a capacitive sensor below the bearing plate. The bearing plate is self-aligned to the 3 hydrostatic pockets. A flexure ensures a proper guidance of the forces, while introducing no further dampening on the setup. The dynamic frequency response up to $5 \mathrm{kHz}$ of the test setup itself was measured. The first eigen frequency is at $2.5 \mathrm{kHz}$, thus the dynamic measurements were taken up to $2 \mathrm{kHz}$. It is therefore assumed that no relevant dynamic behaviour of the test stand itself influences the experimental results.

The test stand is supplied with temperature-controlled oil at $20^{\circ} \mathrm{C}$. The oil is a HLP standardized hydraulic oil with the viscosity class ISO VG 32 . The supply pressure is $10 \mathrm{MPa}$ (100 bar).

Both a classical system with a gap design of $20 \mu \mathrm{m}$ and a novel proposed system with a micro gap design of $5 \mu \mathrm{m}$ are analysed. The hydrostatic resistance of the laminar resistor is adjusted while the pocket geometry remains unchanged.

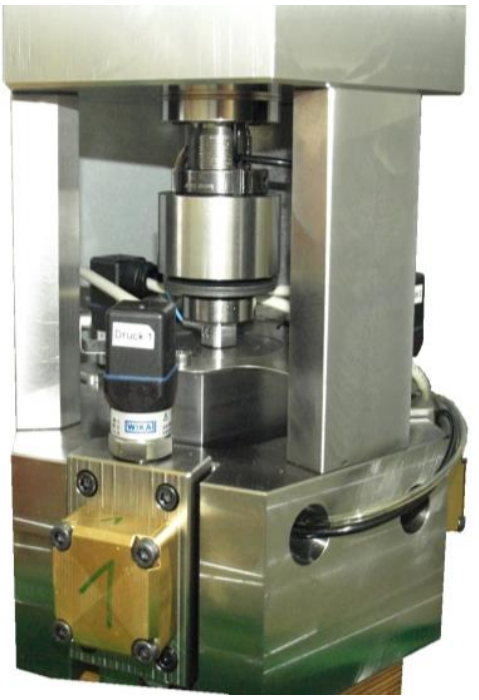

Fig. 6 : The hydraulic test stand.

\section{EXPERIMENTAL}

\subsection{Static Measurements}

For the static measurements, the load is increased in steps until the maximum load of each pocket is reached. The pump pressure equals the pocket pressure. The fluid film thickness is recorded and plotted in relation to the pocket pressure. The theoretical model (static model, after [Wasson 2007]) from section 2.2 is used to create the curves for both fluid film thicknesses.

Fig. 7 shows the measured displacement of the test pocket, which gives the fluid film thickness results. Furthermore, the calculated values are plotted and show a high correlation to the experimental validation. 


\section{(C) HSM \\ 2021 \\ MM Science Journal | www.mmscience.eu \\ ISSN 1803-1269 (Print) | ISSN 1805-0476 (Online) \\ Special Issue | HSM 2021 \\ $16^{\text {th }}$ International Conference on High Speed Machining \\ October 26-27, 2021, Darmstadt, Germany}

DOI: 10.17973/MMSJ.2021_11_2021175

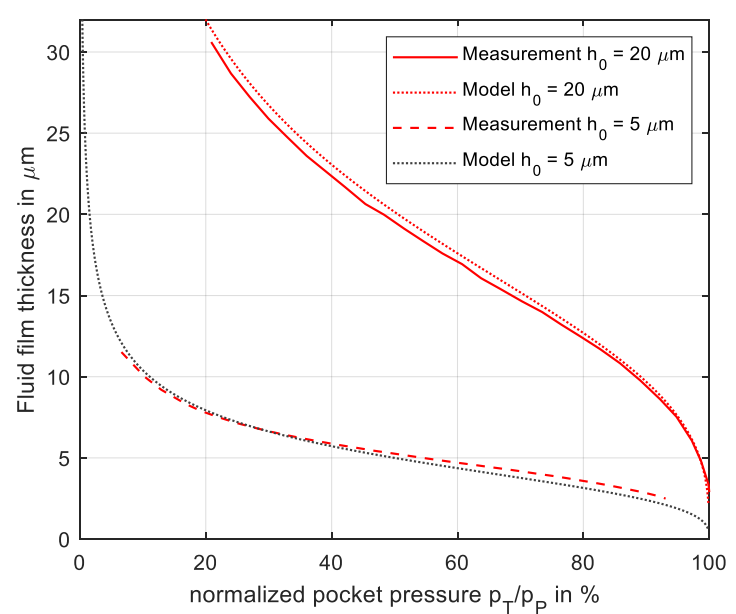

Fig. 7: Static stiffness measurement. The gap height is shown in relation to the pocket pressure.

The characteristic curve of the traditional system (gap height design: $20 \mu \mathrm{m}$ ) shows very low difference between the theoretical, calculated values and the measured experimental results. Looking at the usable load range, the maximum relative deviation is $4 \%$ of the gap height (absolute: $0.8 \mu \mathrm{m}$ ). Above $98 \%$ normalized pump pressure - a range typically not applicable for use- the correlation weakens, and a larger error is noticeable.

The measured gap height is always lower than the calculated one, and the gradient of the measured characteristic curve is flatter than for the theoretical model. For the novel micro gap design, a higher relative deviation from the theoretical model is recorded (see Fig. 7). Because of the smaller gap, the absolute difference is smaller. The areas of interest for the pump pressure are here $20 \%$ (below which the stiffness reserve is insufficient) and 90\% (below which the load reserve is insufficient), commonly the ends of the usable spectrum in the application, as well as the design point $(50 \%)$ where a sensible balance between stiffness and volumetric flow is achieved. Tab. 1 lists the relevant data points.

Tab. 1: Recorded and simulated film thickness at different normalized pocket pressures.

\begin{tabular}{cccccc}
\hline $\begin{array}{c}\text { design } \\
\text { point } \\
\text { in } \mu \mathrm{m}\end{array}$ & $\begin{array}{c}\text { normalized } \\
\text { pocket } \\
\text { pressure in } \\
\%\end{array}$ & $\begin{array}{c}\text { modelled } \\
\text { film } \\
\text { thickness } \\
\text { in } \mu \mathrm{m}\end{array}$ & $\begin{array}{c}\text { measured } \\
\text { film } \\
\text { thickness } \\
\text { in } \mu \mathrm{m}\end{array}$ & $\begin{array}{c}\text { relative } \\
\text { difference } \\
\text { in \% }\end{array}$ & $\begin{array}{c}\text { Absolute } \\
\text { difference } \\
\text { in } \mu \mathrm{m}\end{array}$ \\
\hline 5 & 20 & 7.932 & 7.691 & 3 & 0.241 \\
20 & 20 & 31.540 & 30.610 & 3 & 0.930 \\
5 & 50 & 4.995 & 5.242 & -5 & -0.247 \\
20 & 50 & 20.140 & 19.550 & 3 & 0.590 \\
5 & 90 & 2.369 & 2.811 & -16 & -0.442 \\
20 & 90 & 9.697 & 9.355 & 4 & 0.342 \\
\hline
\end{tabular}

At the design point of $5 \mu \mathrm{m}$ a relative difference of $5 \%$ can be seen. This increases to $15 \%$ relative difference at $90 \%$ pump pressure. The maximum absolute difference is 0.3 $\mu \mathrm{m}$. Comparing the individual stiffness at the design point, the traditional system has a stiffness coefficient of $h_{0}=37$ $\mathrm{N} / \mathrm{\mu m}$, whereas the novel micro gap design shows a stiffness of $h_{0}=137 \mathrm{~N} / \mu \mathrm{m}$.

\subsection{Dynamic Measurements}
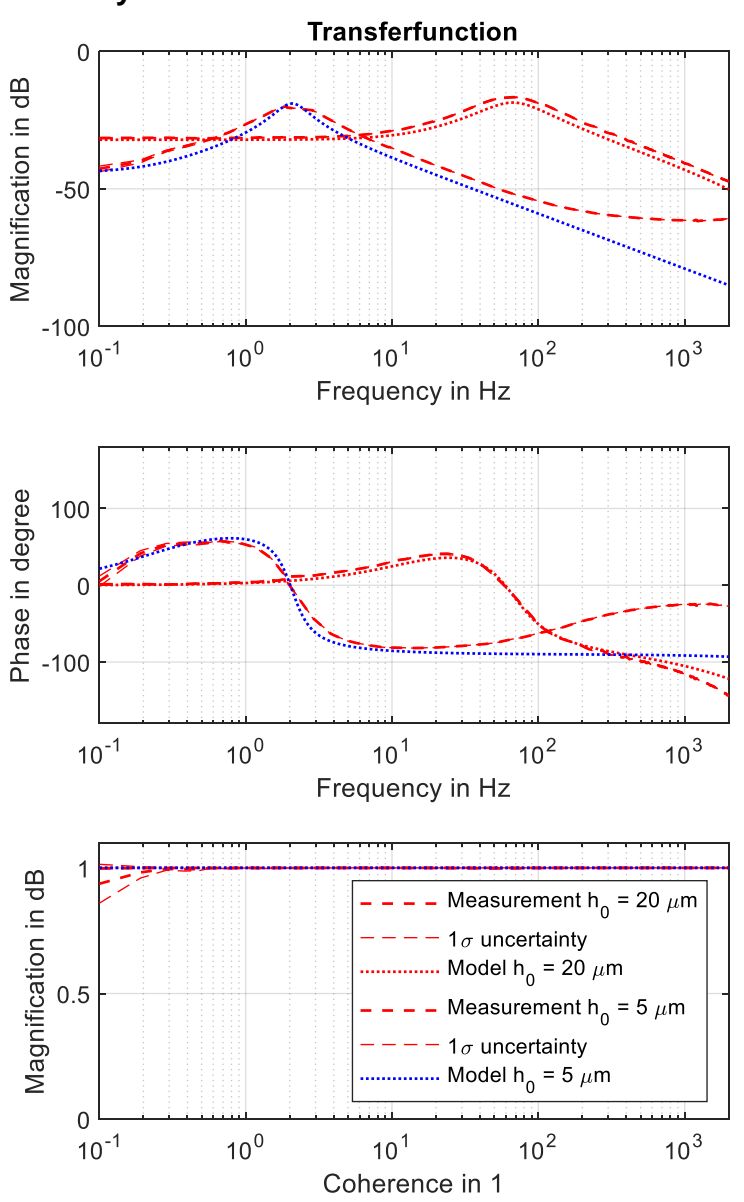

Fig. 8: Dynamic measurement results.

The calculation and measurements of the dynamic stiffness are plotted in a Bode diagram (Fig. 8). Here, the transfer function of the measured force (via force sensor, see fig. 5) to the measured displacement (via capacitive displacement sensor, see fig. 5) is shown. The dynamic compliance $(\mu \mathrm{m} / \mathrm{N})$ is converted to $\mathrm{dB}$, thus making for an easier readability, and enabling the application of system theory to the result. As excitation, a multisine signal, generated by a piezo actuator, is used. The output parameter is the displacement in $\mu \mathrm{m}$. The magnification between the input and output parameter is the amplitude gain, described in $\mathrm{db}$. The phase shift is displayed in degrees, and the frequency is plotted in $\mathrm{Hz}$ on the abscissa. From this, the important dynamic characteristics can be deducted and are shown in Tab. 2.

\subsection{Power consumption}

The flow rate of each hydrostatic design was evaluated at the nominal film thickness through measurement of the volumetric flow. The traditional $20 \mu \mathrm{m}$ gap design shows a flow rate of $0.12 \mathrm{l} / \mathrm{min}$, whereas the micro gap design shows a flowrate of $0.002 \mathrm{l} / \mathrm{min}$. Both systems were operated at an 
identical pump pressure, thus showing a pump power reduction of $98 \%$ for the micro gap design compared to the reference design.

Tab. 2: Stiffness characteristics between a $20 \mu \mathrm{m}$ and 5 um gap design.

\begin{tabular}{|c|c|c|}
\hline Film thickness in $\mu \mathrm{m}$ & 20 & 5 \\
\hline $\begin{array}{l}\text { quasi-static } \\
\text { compliance in } \mathrm{dB} \\
\text { measurement } \\
\text { (simulation) }\end{array}$ & $\begin{array}{c}-31.3 \\
(-32.1)\end{array}$ & $\begin{array}{c}-42.7 \\
(-43.5)\end{array}$ \\
\hline $\begin{array}{c}\text { quasi-static stiffness } \\
\text { in } \mathrm{N} / \mu \mathrm{m} \\
\text { measurement } \\
\text { (simulation) }\end{array}$ & $\begin{array}{c}37 \\
(41)\end{array}$ & $\begin{array}{c}137 \\
(149)\end{array}$ \\
\hline $\begin{array}{l}\text { relative error quasi- } \\
\text { static stiffness }\end{array}$ & $10 \%$ & $8 \%$ \\
\hline $\begin{array}{c}\text { amplitude peak } \\
\text { frequency in } \mathrm{Hz} \\
\text { measurement } \\
\text { (simulation) }\end{array}$ & $\begin{array}{c}67 \\
(67)\end{array}$ & $\begin{array}{c}1,9 \\
(2,1)\end{array}$ \\
\hline $\begin{array}{l}\text { relative error in } \\
\text { amplitude peak } \\
\text { frequency }\end{array}$ & $0 \%$ & $11 \%$ \\
\hline
\end{tabular}

\subsection{Power usage for movement}

While a hydrostatic guideway inside a complex machine tool always requires more energy to supply the fluid film, the lower friction can be advantageous in the power consumption during movements.

To compare this, two similar machining centres are analysed. The Kern Micro Vario has the same dimension and kinematics as the Kern Micro HD, but uses a roller bearing guideway and a servo driven leadscrew. The Kern Micro HD has a micro gap hydrostatic guideway system and is driven via linear motors. Both machines have similar structural bodies in 3 axis linear stage, aggregates, and a comparable weight.

On both machines, the electrical current of the drive system at constant feed rate is recorded. A relatively slow feed rate of $1000 \mathrm{~mm} / \mathrm{min}$ (finishing operations) is compared with a medium speed of $5000 \mathrm{~mm} / \mathrm{min}$ (general machining operations) as well as the maximum rapid feed rate (30000 $\mathrm{mm} / \mathrm{min}$ on the Vario, $60000 \mathrm{~mm} / \mathrm{min}$ on the HD). The torque and the feed force required to move an axis is calculated via recording the electric current in the converter of the machine by means of the torque and force constants. With the torque of the motor (servo) and the speed the mechanical power consumption of the Micro Vario is calculated. With the feed force (linear motor) and the feed rate the mechanical power consumption of the Micro HD is calculated. Through equation 4, the power can be calculated from the torque, respectively the force.

$P_{V}=v \cdot F \quad$ and $\quad P_{V}=2 \pi \cdot \mathrm{n} \cdot \mathrm{M}_{\mathrm{V}}$

The calculated power consumption is shown in Tab. 3 .
Tab. 3: Power consumption between a roller bearing and hydrostatic guideway design.

\begin{tabular}{cccc}
\hline $\begin{array}{c}\text { Feed rate } \\
\text { in mm/min }\end{array}$ & $\begin{array}{c}\text { Micro Vario } \\
\text { Power in W }\end{array}$ & $\begin{array}{c}\text { Micro HD } \\
\text { Power in W }\end{array}$ & $\begin{array}{c}\text { Ratio } \\
\text { HD/Vario }\end{array}$ \\
\hline 1000 & 1.04 & 0.85 & $82 \%$ \\
5000 & 9.18 & 4.45 & $48 \%$ \\
10000 & 22.88 & 9.82 & $43 \%$ \\
30000 & 101.2 & - & - \\
(Fmax) & & & - \\
60000 & - & 90.71 & \\
(Fmax) & & & \\
\hline
\end{tabular}

The power consumption for the axis movement of the hydrostatic machine tool (Micro HD) is always lower than the power consumption of the machine with roller guideways. The relative difference at low velocities (18\% at $1000 \mathrm{~mm} / \mathrm{min}$ ) is smaller than the difference at high velocities $(57 \%$ at $10000 \mathrm{~mm} / \mathrm{min})$.

\section{DISCUSSION}

\section{Static stiffness}

The theoretical model shows a deviation between $5 \%$ (reference system) and $15 \%$ (micro gap design) from the experimental data. The absolute deviation of $0.8 \mu \mathrm{m}(20 \mu \mathrm{m}$ working point) and $0.3 \mu \mathrm{m}$ (5 $\mu \mathrm{m}$ micro gap design) are sufficient for a practical design of the systems. The static stiffness can be increased significantly through the use of a micro gap design. A decrease of the gap height from $20 \mu \mathrm{m}$ to $5 \mu \mathrm{m}$ increases the stiffness by a factor of 4 .

\section{Dynamic stiffness}

The quasi-static use shows a comparative similar positive result as the static stiffness. The amplitude maximum is shifted towards smaller frequencies on a micro gap design. This can, depending on the machine design, be both positive and negative on the response of the machine tool towards excitations. In high-speed cutting and milling machines, this behaviour is often advantageous, because the tooth entry frequency is at a high frequency. A lower amplitude gain is also positive regarding machine dynamics at the amplitude maximum. In the area of high excitation frequencies, a clear advantage for the micro gap design is visible. There, transfer function sharply drops off, decreasing the dynamic pliability.

\section{Energy consumption}

The flow rate of the micro gap design is significantly lower than on a traditional design. The pump power loss can be decreased by $98 \%$. Because of increased friction power losses, this advantage cannot be fully utilized towards lower energy consumption (see chapter 2.1). To compensate the viscose friction loss, the viscosity has to be reduced. Nevertheless, power consumption can be lowered in the double-digit percentage range. This mitigates the 


\section{HSM \\ 2021}

MM Science Journal | www.mmscience.eu

ISSN 1803-1269 (Print) | ISSN 1805-0476 (Online)

Special Issue | HSM 2021

$16^{\text {th }}$ International Conference on High Speed Machining

October 26-27, 2021, Darmstadt, Germany

DOI: 10.17973/MMSJ.2021_11_2021175

drawbacks of a traditional hydrostatic guideway, where the power consumption and heat generated by the aggregates is unwanted.

\section{Power usage for movement}

The power usage to drive a hydrostatic axis compared to a traditional roller bearing axis is always lower at constant feed rate. The power requirement difference is especially significant at higher velocities. While at a low speed (1000 $\mathrm{mm} / \mathrm{min}$ ) the difference is only $0.1 \mathrm{~W}$ absolute, this increases to over $13 \mathrm{~W}$ at $10000 \mathrm{~mm} / \mathrm{min}$. While the Micro Vario has similar kinematics and weight as a Micro HD, the drive system is completely different. A separation of this correlation into causalities is therefore difficult. Modern high quality ball screws typically have an efficiency of above $90 \%$. It can therefore be concluded that for values well above $10 \%$ relative difference, the guideway friction is the driving force behind the lower power consumption. This is recorded for feed rates above $5000 \mathrm{~mm} / \mathrm{min}$ (relative power difference: $52 \%$ ). Therefore, micro gap design hydrostatic guideways are not only advantageous for precision machine tools with their low friction, but also have a noticeable influence on the energy efficiency on high productivity machines. Moreover, a lower friction is advantageous on the heat management of the machine.

\section{SUMMARY}

In conclusion, the properties of hydrostatic guideways are generally advantageous for precision machine tools. The dynamic behaviour, static stiffness and energy consumption of a hydrostatic guideway can be improved via the proposed micro gap design. The response function especially lends itself to be used in dynamic systems with high excitation frequencies, such as HSM and high productivity machine tools.

An increase of the static stiffness by a factor of 4 , a reduction of the pump power by $98 \%$, and a movement power reduction of 18-56 \% was achieved by decreasing the gap height from $20 \mu \mathrm{m}$ to $5 \mu \mathrm{m}$.

\section{REFERENCES}

[Bassani 1992] Bassani, R. e. a., Hydrostatic Lubrication, Amsterdam: Elsevier Science Publishers, 1992.

[Elwell 1960] Elwell, R. C., "Theoretical and experimental analysis," Journal of Basic Engineering, pp. p. 505-511, 1960.

[Ghosh 1982] Ghosh, M. K. e. a., "Dynamic stiffness and damping characteristics of compensated hydrostatic thrust bearings," Journal of Lubrication Technology, pp. p. 491-496, 1982.

[Hale 1991] Hale, L. C., Principles and techniques for designing precision machines., Springfield, USA: National Technical Information Service, 1991.

[Knapp 2011] Knapp, B. e. a., "Ultra-precision oil hydrostatic spindle.," American Society for Precision Engineering, 2011.

[Hunt 1963] Hunt, J. B., "Dynamic characteristics of a hydrostatic thrust bearing," Proceedings of the Institution of Mechanical Engineers, pp. p. 245-257, 1963.
[Lui 2017] Liu, Z. e. a., "A review of hydrostatic bearing system: Research and application," Advances in Mechanical Engineering, pp. p. 1-27, 2017.

[Perovic 2012] Perovic, B., Hydrostatische Führungen und Lager, Berlin Heidelberg: Springer, 2012.

[Rowe 1970] Rowe, B. e. a., "Optimization of externally pressurized bearings for minimum power and low temperature rise.," Tribology, 1970.

[Rowe 1980] Rowe, W., "Dynamic and static properties of recessed hydrostatic journal bearings by small displacement analysis," Journal of Lubrication Technology, pp. p. 71-79, 1980.

[Rowe 1992] Rowe, W. B. e. a., Hydrostatic, aerostatic and hybrid bearing design, Oxford, UK: ButterworthHeinemann, 2012.

[Tonshoff 1995] Tonshoff, H. K., Werkzeugmaschinen Grundlagen, Berlin, Heidelberg: Springer, 1995.

[Wasson 2007] Wasson, K. L., "A comparison of rolling elements and hydrostatic bearing spindles for precision machine tools applications.," American Society for Precision Engineering - Annual Meeting, 2007.

[Weck 2006] Weck, M. e. a., Werkzeugmaschinen Band 2 - Konstruktion und Berechnung, Berlin Heidelberg: Springer, 2006. 